\title{
Interactive Effects of Dehydroepiandrosterone and Testosterone on Cortical Thickness during Early Brain Development
}

\author{
Tuong-Vi Nguyen, ${ }^{1}$ James T. McCracken, ${ }^{2,3}$ Simon Ducharme, ${ }^{1}$ Brett F. Cropp,${ }^{4}$ Kelly N. Botteron, ${ }^{2,5}$ Alan C. Evans, ${ }^{1,2}$ \\ and Sherif Karama ${ }^{1,6}$ \\ ${ }^{1}$ McConnell Brain Imaging Center, Montreal Neurological Institute, McGill University, Montreal, Quebec H3A 2B4, Canada, ${ }^{2}$ Brain Development \\ Cooperative Group (http://www.brain-child.org/brain_group.html), ${ }^{3}$ Department of Child and Adolescent Psychiatry, University of California in Los \\ Angeles, Los Angeles, California 90024, ${ }^{4}$ Division of Health Sciences Informatics, Johns Hopkins School of Medicine, Baltimore, Maryland 21205, \\ ${ }^{5}$ Department of Child Psychiatry and Radiology, School of Medicine, Washington University, St. Louis, Missouri 63130, and ${ }^{6}$ Department of Psychiatry, \\ Douglas Mental Health University Institute, McGill University, Montreal, Quebec H4H 1R3, Canada
}

Humans and the great apes are the only species demonstrated to exhibit adrenarche, a key endocrine event associated with prepubertal increases in the adrenal production of androgens, most significantly dehydroepiandrosterone (DHEA) and to a certain degree testosterone. Adrenarche also coincides with the emergence of the prosocial and neurobehavioral skills of middle childhood and may therefore represent a human-specific stage of development. Both DHEA and testosterone have been reported in animal and in vitro studies to enhance neuronal survival and programmed cell death depending on the timing, dose, and hormonal context involved, and to potentially compete for the same signaling pathways. Yet no extant brain-hormone studies have examined the interaction between DHEA- and testosterone-related cortical maturation in humans. Here, we used linear mixed models to examine changes in cortical thickness associated with salivary DHEA and testosterone levels in a longitudinal sample of developmentally healthy children and adolescents $4-22$ years old. DHEA levels were associated with increases in cortical thickness of the left dorsolateral prefrontal cortex, right temporoparietal junction, right premotor and right entorhinal cortex between the ages of $4-13$ years, a period marked by the androgenic changes of adrenarche. There was also an interaction between DHEA and testosterone on cortical thickness of the right cingulate cortex and occipital pole that was most significant in prepubertal subjects. DHEA and testosterone appear to interact and modulate the complex process of cortical maturation during middle childhood, consistent with evidence at the molecular level of fast/nongenomic and slow/genomic or conversion-based mechanisms underlying androgen-related brain development.

\section{Introduction}

The processes underpinning brain development during middle childhood are particularly important to elucidate given the emergence of behavioral and prosocial skills during this period. This development coincides with adrenarche, a uniquely human endocrine event shared only with great apes and preceding the onset

Received Dec. 16, 2012; revised May 12, 2013; accepted May 21, 2013.

Author contributions: T.-V.N. and S.K. designed research; T.-V.N., J.T.M., K.N.B., and A.C.E. performed research;

J.T.M. and A.C.E. contributed unpublished reagents/analytic tools; T.-V.N., S.D., B.F.C., and S.K. analyzed data; T.-V.N., J.T.M., S.D., and S.K. wrote the paper.

This work was supported by Federal funds from the National Institute of Child Health and Human Development, the National Institute on Drug Abuse, the National Institute of Mental Health, and the National Institute of Neurological Disorders and Stroke (Contracts N01-HD02-3343, N01-MH9-0002, and N01-NS-9$2314,-2315,-2316,-2317,-2319$, and -2320). S.K. was supported by the Fonds de Recherche en Santé du Québec. We would like to acknowledge the Brain Development Cooperative Group, which significantly contributed to the design and data collection of this study.

The authors declare no competing financial interests.

Correspondence should be addressed to Dr. Sherif Karama, McConnell Brain Imaging Center, 3801 University, WB208, Montreal, QC H3A 2B4, Canada. E-mail: sherif.karama@mcgill.ca.

T.-V. Nguyen's present address: Section of Behavioral Endocrinology and Section of Integrative Neuroimaging, National Institutes of Mental Health, Bethesda, MD 20892

DOI:10.1523/JNEUROSCI.5747-12.2013

Copyright $\odot 2013$ the authors $\quad 0270-6474 / 13 / 3310840-09 \$ 15.00 / 0$ of puberty (Campbell, 2011). While dehydroepiandrosterone (DHEA) and its sulfated derivative DHEAS represent the most abundant steroid hormones in circulation across the lifespan (Adams, 1985), their levels increase most significantly during adrenarche between ages 3 and 13 (Remer et al., 2005). DHEA then remains at a steady level until the third decade of life and decreases thereafter, coinciding with synaptic loss/cortical thinning (Salat et al., 2004; Glantz et al., 2007). A variety of neural effects have been ascribed to DHEA and its derivatives: while DHEA has been associated with axonal/dendritic growth (Compagnone and Mellon, 2000; Li et al., 2009), DHEAS appears to increase apoptosis in neural precursors (Zhang et al., 2002). Adrenarche has thus been speculated to play an important role in the extended period of brain development and synaptic pruning in humans (Campbell, 2011). Yet its role in human brain development has never been studied in children and adolescents.

While DHEA represents the primary steroid hormone in circulation during adrenarche, adrenal production of testosterone may also play a role during this developmental period (Remer et al., 2005; Rege, 2012). Prior findings from our group showed that higher testosterone levels tend to be associated with decreased 
cortical thickness (CTh) during adolescence (Nguyen et al., 2013), consistent with in vitro evidence that high testosterone levels may exert anti-proliferative effects (Estrada et al., 2006). Yet in other settings when lower testosterone levels predominate, it may be associated with neuroprotection and increased CTh (Vasconsuelo et al., 2011; Nguyen et al., 2013).

These paradoxical effects of DHEA and testosterone on neuronal survival may rely on different androgen pathways that are more or less active depending on the levels of each hormone: a slow/ genomic pathway requiring changes in DNA transcription and a faster/nongenomic pathway acting mainly through secondmessenger signaling systems (Foradori et al., 2008). In addition, DHEA and testosterone appear to have competing and antagonistic effects on the same final common pathways such as the modulation of intracellular calcium levels (Pérez-Neri et al., 2008; Vasconsuelo et al., 2011). This suggests that androgens may interact in shaping brain development, and this interaction likely varies across the age span depending on the respective levels of each steroid hormone.

Here, we examine longitudinal changes in CTh associated with DHEA and testosterone in a population-based sample of children and adolescents. We take an exploratory approach, hypothesizing that DHEA levels are associated with increased CTh, particularly during adrenarche, and predicting that DHEA may interact with testosterone to modulate CTh in testosterone-sensitive brain regions such as the dorsolateral prefrontal, cingulate, or somatosensory cortices identified in a previous examination of the same sample (Nguyen et al., 2013). We expected no significant sex differences in DHEA-related cortical maturation given previous reports of similar levels of DHEA and its metabolites in boys and girls 3-17 years of age (Remer et al., 2005).

\section{Materials and Methods}

Sampling and recruitment. The National Institutes of Health (NIH) MRI Study of Normal Brain Development is a multisite project providing a normative database to characterize healthy brain maturation (Evans and Brain Development Cooperative Group, 2006). Subjects were recruited across the United States with a population-based sampling method seeking to achieve a representative sample in terms of income level and composition by race and ethnicity based on the US 2000 Census (Evans and Brain Development Cooperative Group, 2006). Informed consent from parents and child assent were obtained for all subjects. Detailed sampling methodology has been described elsewhere (Evans and Brain Development Cooperative Group, 2006). The Objective 1 database (release 4.0) used for this study included 433 healthy children from 4 to 22 years old (226 females, 207 males) who underwent repeated magnetic resonance brain imaging (MRI) every 2 years, with a maximum of three scans over 4 years. To limit the sample to developmentally healthy children, rigorous exclusion criteria were applied, including current or past treatment for DSM-IV axis 1 psychiatric disorders, learning disabilities, evidence of significant axis I disorders on structured parent or child interview (DICA), family history of major axis 1 disorder, family history of inherited neurological disorder or mental retardation due to nontraumatic events, abnormality on neurological examination, gestational age at birth $<37$ weeks or $>42$ weeks, and intrauterine exposure to substances known or highly suspected to alter brain structure or function. After strict quality control of MRI data (see Image processing, below), two samples could be determined (Tables 1,2): a first sample of 255 subjects (143 females, 112 males) for which measures of DHEA levels were available (total 407 scans, 238 scans from female subjects, 169 scans from male subjects) and a second sample of 234 subjects ( 131 females, 103 males) for which measures for both testosterone and DHEA levels were available (total 369 scans, 216 from female subjects, 153 from male subjects).

MRI protocol. A three-dimensional T1-weighted (T1W) Spoiled Gradient Recalled (SPGR) echo sequence from 1.5 tesla scanners was obtained on each participant, with $1 \mathrm{~mm}$ isotropic data acquired sagittally from the entire head for most scanners (slice thickness of $\sim 1.5 \mathrm{~mm}$ was allowed for GE scanners due to their limit of 124 slices). In addition, T2-weighted (T2W) and proton density-weighted (PDW) images were acquired using a two-dimensional (2D) multislice $(2 \mathrm{~mm})$ dual echo fast spin echo (FSE) sequence. Total acquisition time was $\sim 25 \mathrm{~min}$ and was often repeated when indicated by the scanner-side quality control process.

Image processing. All quality-controlled MR images were processed through the CIVET pipeline (version 1.1.9) developed at the MNI for fully automated structural image analysis (Ad-Dab'bagh et al., 2006). The main pipeline processing steps include: (1) Linearly registering native (i.e., original) MR images to standardized MNI-Talairach space based on the ICBM152 dataset (Talairach and Tournoux, 1988; Collins et al., 1994; Mazziotta et al., 1995). This step is implemented to account for gross volume differences between subjects. (2) Correct for intensity nonuniformity artifacts using N3 (Sled et al., 1998). These artifacts are introduced by the scanner and need to be removed to minimize, in the current context, biases in estimating gray matter boundaries. (3) Classify the image into white matter (WM), gray matter (GM), CSF and background using a neural net classifier (INSECT) (Zijdenbos et al., 2002). (4) Fit images with a deformable mesh model to extract two-dimensional inner (WM/GM interface) and outer (pial) cortical surfaces for each hemisphere with the third edition of CLASP. This produces high-resolution hemispheric surfaces with 81,924 polygons each [40,962 vertices (i.e., cortical points) per hemisphere] (MacDonald et al., 2000; Kabani et al., 2001; Kim et al., 2005; Lyttelton et al., 2007). This step places 40,962 cortical points on each hemisphere for each subject. (5) Register both cortical surfaces for each hemisphere nonlinearly to a high resolution average surface template generated from the ICBM152 dataset to establish intersubject correspondence of the cortical points (Mazziotta et al., 1995; Grabner et al., 2006; Lyttelton et al., 2007). (6) Apply a reverse of the linear transformation performed on the images of each subject to allow cortical thickness estimations to be made at each cortical point in the native space of the magnetic resonance image (Ad-Dab'bagh et al., 2005). This avoids having cortical thickness estimations biased by the scaling factor introduced by the linear transformations (i.e., step 1) applied to each subject's brain. (7) Calculate cortical thickness at each cortical point using the tink metric (Lerch and Evans, 2005) and blur each subject's cortical thickness map using a $20 \mathrm{~mm}$ full-width at halfmaximum surface-based diffusion smoothing kernel (a necessary step to impose a normal distribution to corticometric data and to increase signal-to-noise ratio) (Chung et al., 2001).

In addition to the CIVET pipeline, a multistage quality control (QC) process was implemented. The first step was a simple inspection of the raw MR images of each subject. Raw MR images that exhibited gross artifacts (e.g., ringing artifacts) were eliminated from further processing. A second step consisted in inspecting each subject's white/gray matter surface boundaries against their native MR images to ascertain proper placement of the boundaries. In a third step, each subject's white and gray matter surfaces from the final CIVET output were examined. Subjects that exhibited gross white or gray matter artifacts were eliminated from the statistical analyses. This stringent manual QC process was implemented by two independent investigators with an inter-rater reliability of $>0.9$ (Karama et al., 2009).

DHEA and testosterone collection. Over the course of 4 years, during each MRI visit, children provided two separate $1-3 \mathrm{~cm}^{3}$ samples of saliva, collected at two time points during the day, which were assayed by ELISA methods for DHEA and testosterone levels (Salimetrics Salivary DHEA, ELISA; Salimetrics Salivary Testosterone ELISA Kit). DHEA, as opposed to its sulfated hydrophilic derivative DHEAS, is easily measured in saliva and crosses the blood-brain barrier due to its lipophilicity (Vining and McGinley, 1987; Stanczyk, 2006). In contrast to the reported CNS production of DHEA in rats, de novo CNS synthesis of DHEA in humans is unlikely to be significant given the low/negligible levels of P450c17 and cytochrome b5 in the human brain (Baulieu, 1998; Compagnone and Mellon, 2000). Therefore, CNS DHEA levels are representative of the high inflow of DHEA from the periphery, the major portion of which is produced in the adrenal cortex with a small contribution from nerve terminals in the peripheral nervous system (Compagnone and Mellon, 
Table 1. Characteristics of the DHEA sample (means and SDs)

\begin{tabular}{|c|c|c|c|}
\hline $\begin{array}{l}\text { Males and females } N=255 \text { subjects; } \\
\text { Scans: } 407\end{array}$ & $\begin{array}{l}\text { Males } N=112 \text { subjects; } \\
\text { Scans: } 169\end{array}$ & $\begin{array}{l}\text { Females } N=143 \text { subjects; } \\
\text { Scans: } 238\end{array}$ & $\begin{array}{l}\text { Comparisons between } \\
\text { males and females: } \\
p \text { values and significance* }\end{array}$ \\
\hline Age (years) & 13.3 (SD: 3.6) & 13.1 (SD: 3.5$)$ & $p=0.508$ \\
\hline Prepubertal & 11.0 (SD: 2.2) & 10.2 (SD: 1.9) & $p=0.006^{*}$ \\
\hline Postpubertal & 16.7 (SD: 2.2) & 15.7 (SD: 2.5) & $p=0.003^{*}$ \\
\hline Pubertal stage & 2.3 (SD: 1.4) & 2.8 (SD: 1.5$)$ & $p=0.001^{*}$ \\
\hline Prepubertal & $1.3(S D: 0.5)$ & 1.4 (SD: 0.5$)$ & $p=0.183$ \\
\hline Postpubertal & 3.9 (SD: 0.8) & 4.2 (SD: 0.7$)$ & $p=0.027^{*}$ \\
\hline Handedness & $R=144 ; L=25$ & $R=222 ; L=16$ & $p=0.008^{*}$ \\
\hline Prepubertal & $\mathrm{R}=84 ; \mathrm{L}=17$ & $R=103 ; L=10$ & $p=0.079$ \\
\hline Postpubertal & $R=60 ; L=8$ & $R=119 ; L=6$ & $p=0.075$ \\
\hline Total brain volume $\left(\mathrm{mm}^{3}\right)$ & 1366394.0 (SD: 106 502.4) & 1222185.0 (SD: 105 428.7) & $p<0.0001^{*}$ \\
\hline Prepubertal & $1378719.9(99753.0)$ & $1252089.0(101179.5)$ & $p<0.0001^{*}$ \\
\hline Postpubertal & $1348086.4(114$ 107.9) & 1195151.1 (102 206.3) & $p<0.0001^{*}$ \\
\hline DHEA levels (pg/ml) & 148.3 (SD: 143.4) & 159.8 (SD: 162.2) & $p=0.460$ \\
\hline Prepubertal & 110.0 (SD: 110.8$)$ & 89.5 (SD: 107.3) & $p=0.169$ \\
\hline Postpubertal & 205.0 (SD: 166.8) & 223.3 (SD: 177.0) & $p=0.485$ \\
\hline Collection time (min after midnight) & 684.5 (SD: 139.9) & 702.9 (SD: 140.2) & $p=0.193$ \\
\hline Prepubertal & 689.4 (SD: 131.8) & 691.4 (SD: 119.9) & $p=0.910$ \\
\hline Postpubertal & 677.2 (SD: 151.8) & 713.3 (SD: 156.1) & $p=0.123$ \\
\hline
\end{tabular}

*Significance threshold of $p<0.05$, comparing males and females using $t$ test except for handedness for which $\chi^{2}$ was used.

2000; Maninger et al., 2009). This is further confirmed by a study of human subjects in which serum DHEA levels were shown to correlate with CSF DHEA levels (Kancheva et al., 2011). Peripheral DHEA levels may thus be especially representative of CNS levels and relevant to the study of brain developmental changes (Compagnone and Mellon, 2000). Similarly, testosterone easily crosses the blood-brain barrier when not bound to sex hormone-binding globulin. Salivary testosterone measures that free, biologically active portion of circulating testosterone levels, which may be more relevant to studies of brain-hormone associations compared to total serum testosterone levels (Nguyen et al., 2013). Although most samples were obtained mid-morning to early afternoon, a period of reduced diurnal fluctuation for steroid hormones, variability in the collection times led to the selection of the earliest sampling of DHEA and testosterone for each subject to maximize data homogeneity. Indeed, DHEA and testosterone levels have been shown to follow diurnal patterns in response to the pulsatile release of adrenocorticotropic hormone and gonadotropin-releasing hormone, respectively (Stanczyk, 2006; Brambilla et al., 2009).

Pubertal staging. The Pubertal Development Scale (PDS) was administered to all subjects included in this study (Petersen et al., 1988). This scale consists of five items on a four point ordinal scale for each gender and has been shown to have good reliability (coefficient $\alpha: 0.77$ ) and validity $\left(r^{2}=0.61-0.67\right)$ compared to physical examination (Petersen et al., 1988). During an interview with the child/adolescent, questions were asked about physical development. Following the method previously used by Wichstrøm et al., we computed a puberty variable consisting of five stages, representing increasing levels of physical maturity similar to Tanner staging, based on the sum of scores for each of the five items divided by 5 (Dorn et al., 1988; Wichstrøm, 1999): (1) Prepubertal $=0$ to 1.7, (2) Early pubertal $=1.8-2.4$, (3) Midpubertal $=2.5-3$, (4) Late pubertal $=3.1-3.6,(5)$ Postpubertal $=3.7-4$.

A dichotomous puberty variable was created differentiating between pre/ early pubertal (stages 1 and 2) and mid/postpubertal subjects (stages 3, 4, and 5). This allowed us to examine separately: (1) subjects at an earlier stage of physical maturation who are exposed to insignificant levels of gonadal hormones (pre-gonadarche) and (2) subjects more likely to have truly initiated gonadarche with a sustained exposure to gonadal hormones (postgonadarche). We refer to these two groups throughout the text as prepubertal (stages 1 and 2) and postpubertal (stages $3,4,5)$ subjects.

Handedness. A measure of hand preference was adapted from the Edinburgh Handedness Inventory. It included handwriting and seven gestural commands. The criterion for hand preference was defined as at least seven of eight responses with the same hand (Waber et al., 2007).

Statistical analyses. Statistical analyses were done using SurfStat (http://www.math.mcgill.ca/keith/surfstat/) and SPSS 18 (SPSS). Con- trary to previous reports, mean and local cortical thickness trajectories across the broader age range in our total sample have been found to be best described by first-order linear functions in contrast to cubic or quadratic functions (Brain Development Cooperative Group, 2012; Nguyen et al., 2013), and consequently age was modeled as a first-order linear function. Each subject's absolute native-space CTh was linearly regressed against DHEA at each cortical point after controlling for the effects of age, sex, total brain volume, collection time, scanner, and handedness. Linear mixed-effects designs were used to model the relationship between DHEA and CTh while taking into account the within- and between-individual variances in this longitudinal sample. These models were run separately in all subjects and then in the prepubertal and postpubertal groups. Age or sex differences in the associations between DHEA and CTh were tested using models with the double-interaction terms "DHEA by age" and "DHEA by sex" controlling for all of the aforementioned covariates. To illustrate differences in the association between DHEA levels and CTh for subjects at different ages, linear mixed-effects models were run at different centered ages (from ages 4 to 22). This approach is similar to other published methods, and uses a modified age term to examine group differences at each age based on values estimated from developmental trajectories modeled on acquired data for all subjects (Shaw et al., 2006). Finally, we examined the "DHEA by testosterone" and "DHEA by testosterone by sex" interactions using full-factorial models. Of note, sex differences in testosterone-related cortical maturation have been previously examined in the same sample (Nguyen et al., 2013). A whole-brain correction, using random field theory (RFT) with $p<0.05$, was used in all analyses to control for multiple comparisons (Worsley et al., 2004).

\section{Results}

\section{Sample characteristics}

Tables 1 and 2 show comparisons for the main variables of interest between males and females in the complete sample, as well as in the prepubertal and postpubertal groups. Table 1 outlines sample characteristics in the DHEA-only sample and Table 2 outlines the sample characteristics in the DHEA and testosterone sample. In the complete sample, there were no significant differences in age between males and females. Comparing prepubertal males and females on one hand, and postpubertal males and females on the other hand, age differences were significant, as expected given the well-replicated data reporting an earlier onset of puberty in females compared with age-matched males (Dorn 
Table 2. Characteristics of the DHEA and testosterone sample (means and SDs)

\begin{tabular}{|c|c|c|c|}
\hline $\begin{array}{l}\text { Males and females } N=234 \text { subjects; } \\
\text { Scans: } 369\end{array}$ & $\begin{array}{l}\text { Males } N=103 \text { subjects; } \\
\text { Scans: } 153\end{array}$ & $\begin{array}{l}\text { Females } N=131 \text { subjects; } \\
\text { Scans: } 216\end{array}$ & $\begin{array}{l}\text { Comparisons between males and females: } \\
p \text { values and significance* }\end{array}$ \\
\hline Age (years) & 13.3 (SD: 3.6) & 13.2 (SD: 3.5$)$ & $p=0.892$ \\
\hline Prepubertal & 11.0 (SD: 2.3) & 10.2 (SD: 2.0) & $p=0.014^{*}$ \\
\hline Pubertal stage & 2.3 (SD: 1.4) & 2.9 (SD: 1.5) & $p<0.0001^{*}$ \\
\hline Prepubertal & 1.3 (SD: 0.5$)$ & 1.4 (SD: 0.5$)$ & $p=0.124$ \\
\hline Postpubertal & $4.0(0.8)$ & 4.2 (SD: 0.7$)$ & $p=0.066$ \\
\hline Postpubertal & $\mathrm{R}=55 ; \mathrm{L}=5$ & $R=115 ; L=5$ & $p=0.250$ \\
\hline Total brain volume $\left(\mathrm{mm}^{3}\right)$ & 1366528.8 (SD: 103 066.7) & 1216609.8 (SD: 106716.5$)$ & $p<0.0001^{*}$ \\
\hline Prepubertal & $1377442.4(96250.8)$ & $1245476.6(104898.8)$ & $p<0.0001^{*}$ \\
\hline Postpubertal & 1349612.7 (111 545.7) & $1193516.3(102864.8)$ & $p<0.0001^{*}$ \\
\hline DHEA levels (pg/ml) & 147.3 (SD: 142.2) & 167.1 (SD: 166.1) & $p=0.234$ \\
\hline Prepubertal & $109.6(110.0)$ & $92.9(110.4)$ & $p=0.299$ \\
\hline Collection time (min after midnight) & 686.8 (SD: 131.8) & 702.3 (SD: 142.0) & $p=0.286$ \\
\hline Prepubertal & 696.2 (SD: 112.6) & 687.9 (SD: 124.8) & $p=0.635$ \\
\hline Postpubertal & 672.2 (SD: 157.0) & 713.9 (SD: 154.0) & $p=0.091$ \\
\hline
\end{tabular}

*Significance threshold of $p<0.05$, comparing males and females using $t$ test except for handedness for which $\chi^{2}$ was used.

Table 3. Number of subjects and longitudinal scans by gender and pubertal status* for the DHEA sample

\begin{tabular}{|c|c|c|c|c|c|c|c|c|c|}
\hline & \multicolumn{3}{|l|}{ Males } & \multicolumn{3}{|c|}{ Females } & \multicolumn{3}{|l|}{ Total $N$} \\
\hline & Prepub & Postpub & Total & Prepub & Postpub & Total & Prepub & Postpub & Total \\
\hline \multirow[t]{2}{*}{ DHEA } & $N: 73$ & $N: 52$ & $N: 112$ & $N: 87$ & $N: 81$ & $N: 143$ & $N: 160$ & N: 133 & $N: 255$ \\
\hline & S: 101 & S: 68 & S: 169 & S: 113 & S: 125 & S: 238 & S: 214 & S: 193 & S: 407 \\
\hline \multirow[t]{2}{*}{$1 \mathrm{MRI}$ scan } & $N: 48$ & $N: 39$ & $N: 65$ & $N: 65$ & $N: 46$ & $N: 72$ & $N: 113$ & $N: 85$ & $N: 137$ \\
\hline & S: 48 & S: 39 & S: 65 & S: 65 & $N: 46$ & S: 72 & S: 113 & S: 85 & S: 137 \\
\hline \multirow[t]{2}{*}{2 MRI scans } & $N: 22$ & $N: 10$ & $N: 37$ & $N: 18$ & $N: 26$ & $N: 47$ & $N: 40$ & $N: 36$ & $N: 84$ \\
\hline & S: 44 & S: 20 & S: 74 & s: 36 & $N: 52$ & S: 94 & S: 80 & S: 72 & S: 168 \\
\hline \multirow[t]{2}{*}{3 MRI scans } & $N: 3$ & $N: 3$ & $N: 10$ & $N: 4$ & $N: 9$ & $N: 24$ & $N: 7$ & $N: 12$ & $N: 34$ \\
\hline & S: 9 & S: 9 & S: 30 & S: 12 & S: 27 & S: 72 & S: 21 & s: 36 & S: 102 \\
\hline
\end{tabular}

*Of note, although the number of scans adds up across different gender and pubertal categories, combining numbers for the prepubertal and postpubertal subjects will not lead to the indicated total number of subjects. This is because some subjects have had several scans over the years: for example, some scans may have been completed when a subject was in the prepubertal stage, while some scans may have been completed when the same subject was in the postpubertal stage; therefore this subject may be counted toward the number of subjects for both the prepubertal and postpubertal groups. Prepub, Prepubertal; Postpub, postpubertal; $N$, number of subjects; $S$, number of scans.

Table 4. Number of subjects and longitudinal scans by gender and pubertal status* for the DHEA and testosterone sample

\begin{tabular}{|c|c|c|c|c|c|c|c|c|c|}
\hline & \multicolumn{3}{|l|}{ Males } & \multicolumn{3}{|l|}{ Females } & \multicolumn{3}{|l|}{ Total } \\
\hline & Prepub & Postpub & Total & Prepub & Postpub & Total & Prepub & Postpub & Total \\
\hline \multirow[t]{2}{*}{ DHEA and testosterone } & $N: 68$ & $N: 47$ & $N: 103$ & $N: 75$ & $N: 76$ & $N: 131$ & $N: 143$ & $N: 127$ & $N: 234$ \\
\hline & S: 93 & S: 60 & S: 153 & S: 96 & S: 120 & S: 216 & S: 189 & S: 180 & S: 369 \\
\hline \multirow{2}{*}{$1 \mathrm{MRI}$ scan } & $N: 45$ & $N: 36$ & $N: 60$ & $N: 56$ & $N: 48$ & $N: 65$ & N: 101 & $N: 84$ & N: 125 \\
\hline & S: 45 & s: 36 & S: 60 & S: 56 & S: 48 & S: 65 & S: 101 & S: 84 & S: 125 \\
\hline \multirow[t]{2}{*}{$2 \mathrm{MRI}$ scans } & $N: 21$ & $N: 9$ & $N: 36$ & $N: 17$ & $N: 24$ & $N: 47$ & $N: 38$ & $N: 33$ & $N: 83$ \\
\hline & S: 42 & S: 18 & S: 72 & $N: 34$ & S: 48 & S: 94 & S: 76 & S: 66 & S: 166 \\
\hline \multirow[t]{2}{*}{3 MRI scans } & $N: 2$ & $N: 2$ & $N: 7$ & $N: 2$ & $N: 8$ & $N: 19$ & $N: 4$ & $N: 10$ & $N: 26$ \\
\hline & S: 6 & S: 6 & S: 21 & S: 6 & S: 24 & S: 57 & s: 12 & S: 30 & S: 78 \\
\hline
\end{tabular}

*See Table 3 for note and conventions. $N$, Number of subjects; S, number of scans.

et al., 2006). In the complete sample, more males tended to be left-handed as opposed to females, consistent with the higher proportion of left-handers previously reported in males (Rentería, 2012). In all groups, total brain volume was higher in males compared with females, in line with the absolute difference in intracranial and total brain volumes previously reported between males and females (Brain Development Cooperative Group, 2012; Giedd et al., 2012). As predicted, there were no sex differences in DHEA levels in any of the comparison groups, while testosterone levels were higher in males than in females in the complete sample, a difference driven by the postpubertal group (means and SDs displayed in Tables 1,2). Tables 3, 4 outline the number of longitudinal scans in each group, including the complete sample, males and females, and the prepubertal and postpubertal groups. Detailed social and demographic comparisons between males and females have been published elsewhere (Nguyen et al., 2013).

\section{DHEA: positive associations with cortical thickness in prepubertal subjects}

The main effect of DHEA was examined in the complete sample (255 subjects, 407 scans) and then in the prepubertal (160 sub- 


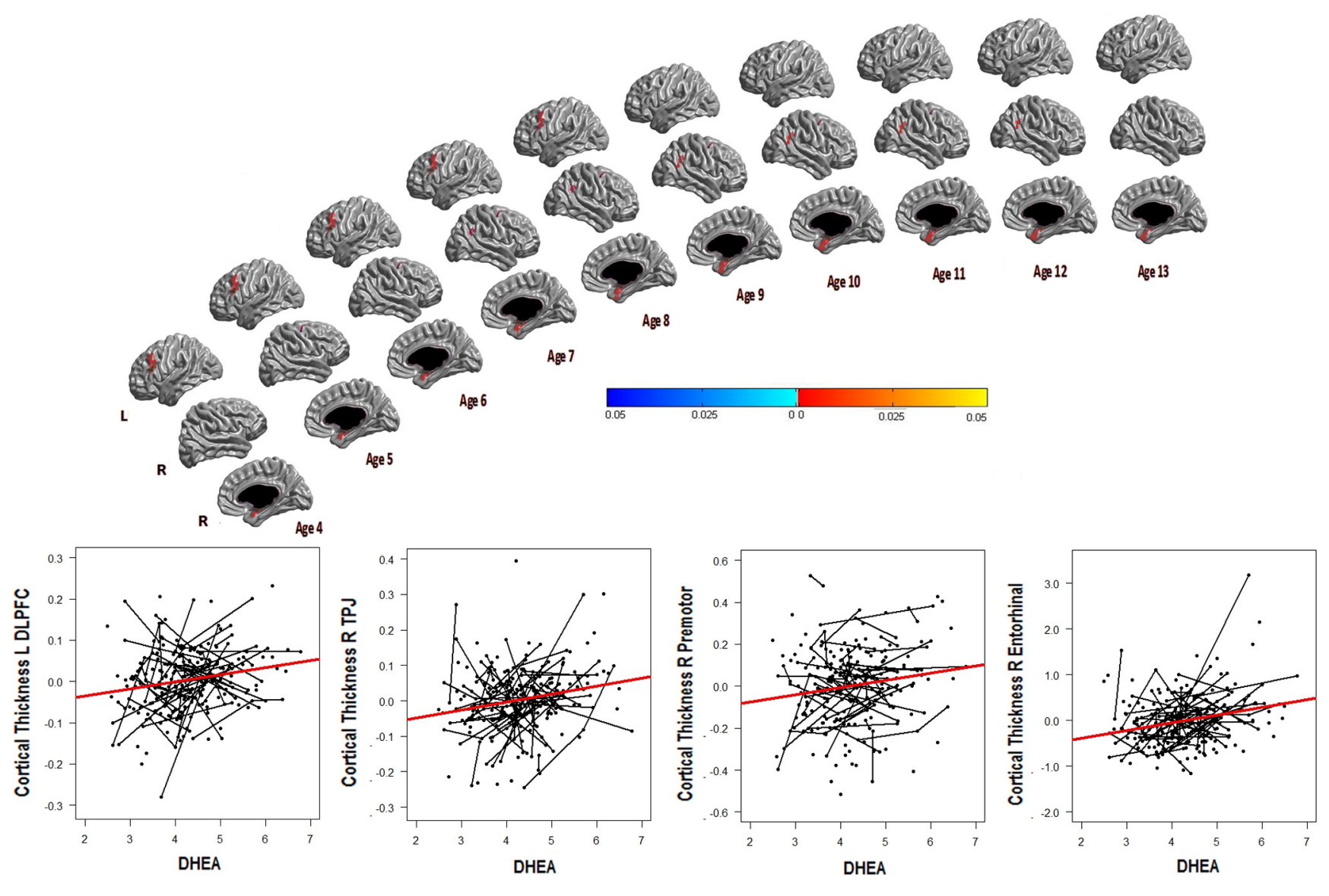

Figure 1. Positive associations between DHEA and cortical thickness across the age span: the relationship between DHEA and cortical thickness is displayed for each age point between ages $4-13$. There were no significant associations between ages $14-22$. From top to bottom, the brain views include a left lateral view, followed by a right lateral view, and then a right sagittal view. There were positive associations between DHEA and the left dorsolateral prefrontal cortex (L_DLPFC) between ages $4-8$, the right temporoparietal junction between ages 7-12 (R_TPJ), the right premotor cortex (R_premotor) between ages 5-11, and the right entorhinal/perirhinal cortex (R_entorhinal) between ages $4-13$. The graphs display the relationship between DHEA and mean cortical thickness of each region in the age range of interest, with longitudinal trajectories outlined for subjects with 2 or more data points. A correction for multiple-comparisons using whole-brain random field theory was applied to all analyses. Note that standardized residuals were used for cortical thickness values on the $y$-axis, and the natural logarithm of DHEA was used on the $x$-axis to improve visualization of all data points.

jects, 214 scans) and postpubertal (133 subjects, 193 scans) groups. There were no significant DHEA-CTh associations in the complete sample. Consistent with the hypothesized association between DHEA and cortical maturation during adrenarche, DHEA was associated with CTh in specific regions of the left frontal, right temporal, and right parietal lobes in the prepubertal group ( $r$ value of maximal significance $=0.15$ ). There were no significant DHEA-CTh associations in the postpubertal group.

\section{DHEA: positive associations with cortical thickness from ages} 4 to 13

To explore the difference in findings between the prepubertal and postpubertal groups, the interaction between DHEA and age was examined in the complete sample (255 subjects, 407 scans), and revealed DHEA-related associations with CTh that significantly varied across the age span. A subsequent analysis at each age point revealed positive associations between DHEA and CTh in several brain regions between the ages of 4 and 13 years old. More specifically, DHEA was positively associated with CTh of the left dorsolateral prefrontal cortex (DLPFC; Brodmann 9) from ages 4 to 8 ( $r$ value of maximal significance $=0.2$ ), the right premotor cortex (PM) (Brodmann 6 ) from ages 5 to 11 ( $r$ value of maximal significance $=0.2$ ), the right temporoparietal junction (TPJ; angular and supramarginal gyrus; Brodmann 39, 40) from ages 7 to $12(r$ value of maximal significance $=0.2)$, and the right entorhinal/perirhinal cortex (ER) (Brodmann 28, 34, 35) from ages 4 to $13(r$ value of maximal significance $=0.2$; Fig. 1$)$. There were no significant DHEA-CTh associations in the 14 to 22 age group.

\section{DHEA and sex: no significant interaction on \\ cortical thickness}

The interaction between DHEA and sex was examined in the complete sample (255 subjects, 407 scans) and then in the prepubertal (160 subjects, 214 scans) and postpubertal groups (133 subjects, 193 scans). Consistent with the absence of sex differences in DHEA levels, there was no significant interaction between DHEA and sex on CTh in the complete sample. There was also no significant interaction between DHEA and sex in the prepubertal or postpubertal groups.

\section{DHEA by testosterone interactions}

The interaction between DHEA and testosterone was examined in the complete sample (234 subjects, 369 scans) and then in the prepubertal (143 subjects, 189 scans) and postpubertal (127 subjects, 180 scans) groups. In the complete sample, there was a significant interaction between DHEA and testosterone involving the right anterior cingulate cortex (ACC; Brodmann 32; $r$ value of maximal significance $=0.2$; Fig. 2 ). In the prepubertal 


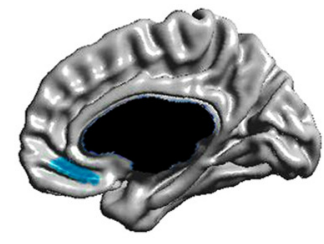

All subjects

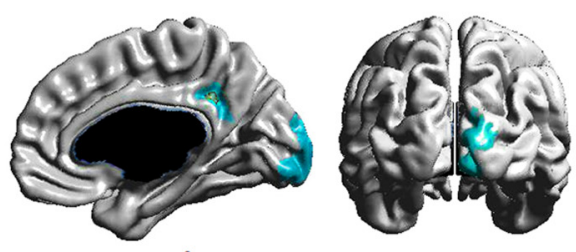

Pre/early pubertal subjects
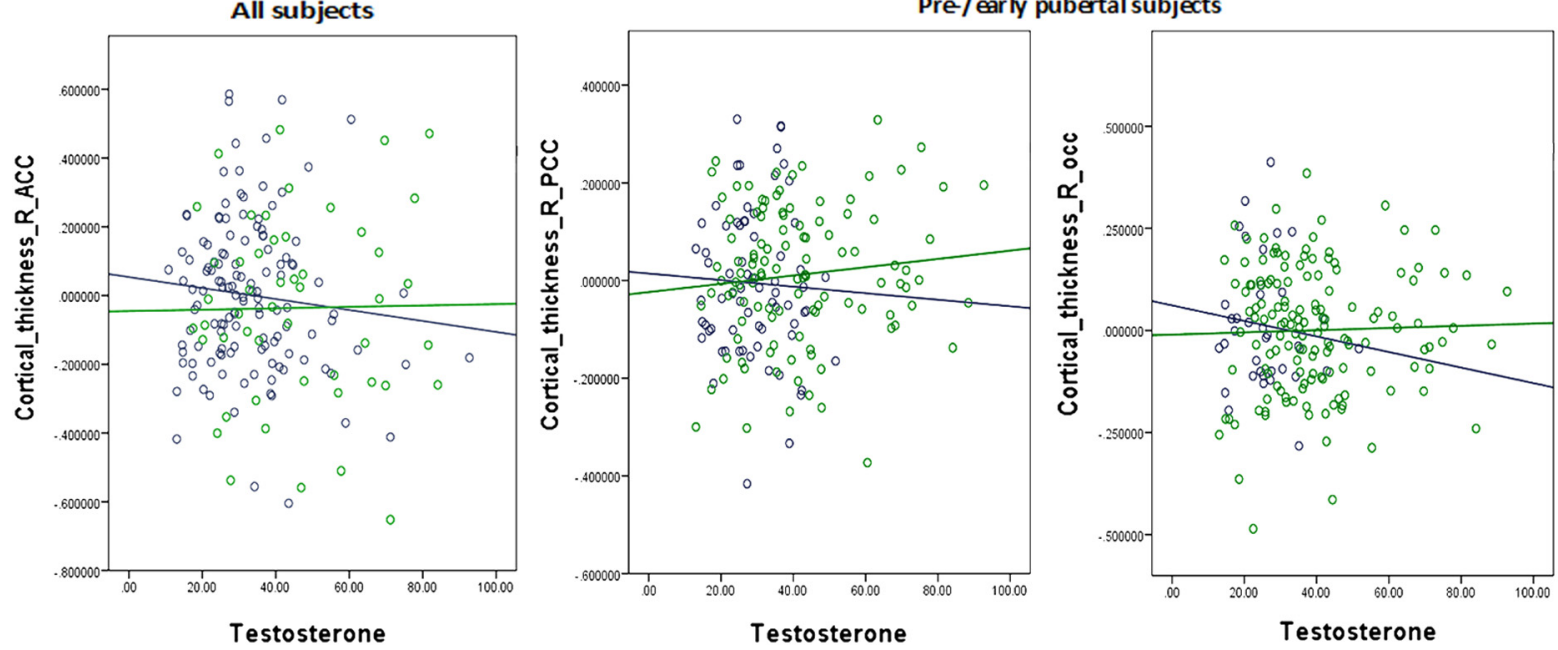

DHEA_groups

O LOW DHEA $O$ High DHEA Low DHEA High DHEA

Figure 2. Interactive effects of DHEA and testosterone on cortical thickness: brain figures show regions with a significant DHEA by testosterone interaction on cortical thickness: (1) in all subjects: the right anterior cingulate cortex ( $\left.R \_A C C\right) ;(2)$ in prepubertal subjects: the right posterior cingulate cortex $\left(R \_P C C\right)$ and the right occipital pole $\left(R \_o c c\right)$. The graphs illustrate the relationship between testosterone and mean cortical thickness for each region, with the blue line representing subjects with low DHEA levels and the green line representing subjects with high DHEA levels. Higher DHEA levels mitigate the negative relationship between high testosterone levels and cortical thickness, while the opposite relationship is present in a low-testosterone context, such that testosterone mitigates the negative relationship between DHEA and cortical thickness. A correction for multiple-comparisons using whole-brain random field theory was applied to all analyses. Note that standardized residuals were used for cortical thickness values on the $y$-axis, and graph windows were restricted to a specific range of testosterone levels to facilitate comparisons across scatter plots.

group, there was also a significant interaction between DHEA and testosterone in the right posterior cingulate gyrus (PCC; Brodmann 23) and occipital pole (OP; Brodmann 17, 18; $r$ value of maximal significance $=0.3$ for both regions; Fig. 2). There was no significant interaction between DHEA and testosterone in the postpubertal group. The complex interaction present in the complete sample and the prepubertal group showed antagonistic effects of DHEA and testosterone that varied relative to the hormonal context. More specifically, in a high-testosterone context, higher DHEA levels were associated with a relative preservation of CTh while lower DHEA levels were associated with reduced $\mathrm{CTh}$ of the right cingulate cortex and occipital pole. In contrast, in a low-testosterone context, there was a reversal of that relationship in the same brain areas such that, for a certain testosterone level, higher DHEA levels were associated with decreased CTh compared with lower DHEA levels. There was no significant sex effect on the interaction between DHEA and testosterone in the complete sample (234 subjects, 369 scans) or in the prepubertal (143 subjects, 189 scans) or postpubertal groups (127 subjects, 180 scans).

\section{Discussion}

This is the first study examining DHEA-CTh associations and the interaction between testosterone and DHEA on CTh in humans. These findings are remarkable because they show hormonal impacts on the brain during early/middle childhood in contrast to the general expectation that the brain is not shaped by hormones until puberty/gonadarche. Findings that DHEA is associated with an increase in CTh from ages $4-13$ are consistent with the timing of adrenarche (Remer et al., 2005), as well as animal models showing neurotrophic effects of DHEA (Suzuki et al., 2004) in- dependent of its conversion to estrogens or other androgens (Marx et al., 2000; Zhang et al., 2002; Suzuki et al., 2004). Increases in CTh may be driven mostly by intracortical glial cell proliferation (Carlo and Stevens, 2013), although glial proliferation itself may be modulated by a variety of neurotrophic processes, including synaptogenesis, axonal growth, vascular changes, or neuroprotection against synaptic pruning (Fields and Burnstock, 2006; Zatorre et al., 2012). During early, prepubertal brain development, a period marked by increased metabolic stress, DHEA may act through several mechanisms to promote neurotrophic changes: (1) its antiglucocorticoid effects (Kaminska et al., 2000; Karishma and Herbert, 2002); (2) an increase in mitochondrial antioxidant potential (Patel and Katyare, 2007); (3) a decrease in NMDA-related neurotoxicity (Kume et al., 2002; Kurata et al., 2004; Li et al., 2009), (4) activation of neurotrophin nerve growth factor (NGF) pathways (Lazaridis et al., 2011), and/or (5) binding to microtubule-associated proteins such as MAP2C (Laurine et al., 2003). Still, more research is needed to determine which of these mechanisms are particularly critical in human brain development.

DHEA was not shown to be associated with increases in CTh beyond age 13. This absence of significant associations in older adolescents/young adults is consistent with the lack of significant change in the brain weight of young adult rodents treated with DHEAwhile developing rats similarly treated showed an increase in brain weight (Patel and Katyare, 2006). DHEA effects may thus be timeand dose-dependent, with certain ages and doses associated with different neurotrophic effects (Zhang et al., 2002; Li et al., 2009).

Consistent with this hypothesis, higher DHEA levels were shown in this study to mitigate the negative relationship between 
testosterone levels and CTh in a high-testosterone context, while the opposite relationship was observed in a lowtestosterone context, such that testosterone mitigated the negative relationship between DHEA and CTh. This complex interaction parallels reports of both proliferative and antiproliferative changes observed with DHEA and testosterone in vitro (Maninger et al., 2009; Vasconsuelo et al., 2011). Similar to neurotrophic changes, anti-proliferative processes may be driven by a variety of mechanisms, including synaptic pruning, glial, and vascular changes or cell shrinkage (Zatorre et al., 2012). These paradoxical effects may rely on two competing and timedependent androgen pathways: a slower, conversion-dependent or genomic, nuclear receptor pathway that relies mostly on changes in DNA transcription and a faster, nongenomic membrane receptor pathway relying mainly on second-messenger signaling systems (Foradori et al., 2008). The fast-acting, nongenomic pathway appears to be most active when high hormonal levels predominate, while the slower conversiondependent or genomic pathway may be more active when lower hormonal levels are present (Foradori et al., 2008). Fast-acting, nongenomic testosterone-related activation of the phosphatidylinositol pathway has been associated with increased intracellular calcium and decreased neuronal survival in the context of high testosterone levels (Estrada et al., 2006), while DHEA-specific neuroprotective effects mediated by its fast-acting, nongenomic decrease in NMDA-induced calcium release may predominate at higher DHEA levels (Kume et al., 2002). In a low-testosterone and DHEA context, slow, genomic mechanisms involving the nuclear androgen receptor has been associated with increased testosterone-related neuronal survival (Foradori et al., 2008), while the relatively slower conversion of DHEA to DHEAS may be associated with anti-proliferative effects through inhibition of the AKT pathway (Zhang et al., 2002). While these mechanisms of interaction require further investigation, they represent convergent pathways through which DHEA and testosterone can modulate neuronal/glial development, an interaction that is reported here for the first time in the context of dynamic brain development in humans.

DHEA-related increases in CTh occurred only in specific brain areas in this study. These regional effects may be related to a critical concentration of NMDA, $\sigma-1$, NGF, or MAP2 receptors, and/or regional differences in enzymatic activity converting DHEA to its derivatives, the latter being supported by findings of variable DHEA concentrations across the brain postmortem (Lacroix et al., 1987). DHEA-responsive brain areas during adrenarche may represent sites of neurotrophic changes during significant developmental processes of middle childhood. Interestingly, adrenarche also coincides with the emergence of many forms of anxiety, mood, tic, and disruptive disorders (Costello et al, 2003; Kessler et al., 2005). However, the direct relationships between DHEA and child behavior remain poorly understood, with the possible exception of increased adrenal androgens associated with disruptive behavior (Van Goozen et al., 2000; Dmitrieva et al., 2001). The scarcity of these studies renders any statement pertaining to links between DHEA-associated cortical thickening and behavior highly speculative. Nonetheless, it is intriguing that associations between DHEA and cortical thickening coincide, in time, with known behavioral changes that are, at least partly, supported by the very same regions where associations between DHEA and cortical thickness have been observed here. For example, the association of DHEA with CTh of the right TPJ in children ages 7-12 is consistent with the development of mentalizing and differentiation of this region between 7 and 11 years old (Saxe et al., 2009), whereas the association between DHEA and CTh of the left DLPFC between ages 4-8 parallels reports of increased activation in this region associated with improved language/behavioral control across the same age range (Rueda et al., 2005; Szaflarski et al., 2006). Similarly, DHEA-related maturation of the right premotor cortex between ages 5-11 partially overlaps with previous reports of developmental changes in spatial working memory in children ages 8-11 (Nelson et al., 2000). Still, definitive statements about DHEA-related developmental changes in behavior and executive control will only be warranted if confirmed by direct studies assessing these relationships.

We have also observed interactive effects of DHEA and testosterone affecting CTh of the cingulate cortex and OP. One can speculate that the requirement for finely tuned hormonal modulation of CTh in these regions is consistent with the need for specific synaptic/glial modulation to integrate multimodal information. Accordingly, the ventral ACC is thought to integrate socio-affective processes (Amodio and Frith, 2006); the PCC appears to integrate self-referential mental thoughts during rest (Fransson and Marrelec, 2008); and the OP participates in the semantic integration of visual/language information (Amedi et al., 2004). Connections to and from these regions were shown to progress from childhood to adulthood, with the ventral ACC and PCC viewed as key components of a functional default network that evolves from weakly connected nodes to a more integrated system with age (Fair et al., 2009). Mentalizing processes also strongly activate the ventral ACC in children and adolescents, moving posteriorly toward a stronger activation of the TPJ with age (Blakemore et al., 2007; Moriguchi et al., 2007; Pfeifer et al., 2007). These results have been interpreted as reflecting a change in the relationship between the ventral ACC and TPJ over time to integrate the socio-cognitive perspective of the self versus others (Blakemore, 2008). Finally, the right OP has been hypothesized to connect with prefrontal language areas, consistent with reports of incremental and simultaneous activation of left prefrontal regions and right $\mathrm{OP}$ in the development of language control in children ages 5-11 (Szaflarski et al., 2006).

\section{Strengths and limitations}

Peripheral DHEA levels represent central DHEA and DHEAS levels, and therefore differential effects of DHEA/DHEAS cannot be distinguished in this study. Variation in collection time of salivary samples was present, although this was controlled for in the analyses. We did not directly examine associations between DHEA-related brain development and behavioral changes, and therefore inferences about the developmental skills acquired during this period cannot be confirmed. In addition, given the limitations of CTh as a measure of microstructural cortical changes, we cannot state with great certainty which proliferative or antiproliferative effects predominate in a specific developmental period. Yet this is the first study examining interactive effects of DHEA and testosterone on the cortex of children/adolescents, and the results point to the relevance of adrenarche as a critical brain developmental period as well as the importance of appraising hormonal levels together rather than in isolation. The generalizability of these findings is supported by the broad age range examined in a longitudinal, representative sample.

\section{Conclusions}

DHEA appears to exert neurotrophic effects during adrenarche and this influence was shown to change with age and specific hormonal context. Positive associations between DHEA and CTh during middle childhood in key brain regions known to integrate 
networks of emotional regulation and cognitive control may reflect the neurotrophic processes necessary to establish longdistance cortical connections in adulthood. The complex interaction between DHEA and testosterone is consistent with molecular evidence of slow conversion-based/genomic and fast nongenomic mechanisms mediating androgen-related brain development.

\section{References}

Adams JB (1985) Control of secretion and the function of C19-delta 5-steroids of the human adrenal gland. Mol Cell Endocrinol 41:1-17. CrossRef Medline

Ad-Dab'bagh Y, Singh V, Robbins S, Lerch J, Lyttelton O, Fombonne E, Evans AC (2005) Native space cortical thickness measurement and the absence of correlation to cerebral volume. Paper presented at the 11th Annual Meeting of the Organization for Human Brain Mapping, Toronto, Ontario, Canada, June.

Ad-Dab'bagh Y, Lyttelton O, Muehlboeck J (2006) The CIVET imageprocessing environment: a fully automated comprehensive pipeline for anatomical neuroimaging research. Paper presented at the Organization for Human Brain Mapping 12th meeting, Florence, Italy, June.

Amedi A, Floel A, Knecht S, Zohary E, Cohen LG (2004) Transcranial magnetic stimulation of the occipital pole interferes with verbal processing in blind subjects. Nat Neurosci 7:1266-1270. CrossRef Medline

Amodio DM, Frith CD (2006) Meeting of minds: the medial frontal cortex and social cognition. Nat Rev Neurosci 7:268-277. CrossRef Medline

Baulieu EE (1998) Neurosteroids: a novel function of the brain. Psychoneuroendocrinology 23:963-987. CrossRef Medline

Blakemore SJ (2008) The social brain in adolescence. Nat Rev Neurosci 9:267-277. CrossRef Medline

Blakemore SJ, den Ouden H, Choudhury S, Frith C (2007) Adolescent development of the neural circuitry for thinking about intentions. Soc Cogn Affect Neurosci 2:130-139. CrossRef Medline

Brain Development Cooperative Group (2012) Total and regional brain volumes in a population-based normative sample from 4 to 18 years: the NIH MRI study of normal brain development. Cereb Cortex 22:1-12. CrossRef Medline

Brambilla DJ, Matsumoto AM, Araujo AB, McKinlay JB (2009) The effect of diurnal variation on clinical measurement of serum testosterone and other sex hormone levels in men. J Clin Endocrinol Metab 94:907-913. Medline

Campbell BC (2011) Adrenarche and middle childhood. Hum Nat 22:327349. CrossRef Medline

Carlo CN, Stevens CF (2013) Structural uniformity of neocortex, revisited. Proc Natl Acad Sci U S A 110:1488-1493. CrossRef Medline

Chung MK, Worsley KJ, Taylor J, Ramsay JO, Robbins S, Evans AC (2001) Diffusion smoothing on the cortical surface. Neuroimage 13:S95.

Collins DL, Neelin P, Peters TM, Evans AC (1994) Automatic 3D intersubject registration of $\mathrm{MR}$ volumetric data in standardized Talairach space. J Comput Assist Tomogr 18:192-205. CrossRef Medline

Compagnone NA, Mellon SH (2000) Neurosteroids: biosynthesis and function of these novel neuromodulators. Front Neuroendocrinol 21:1-56. CrossRef Medline

Costello EJ, Mustillo S, Erkanli A, Keeler G, Angold A (2003) Prevalence and development of psychiatric disorders in childhood and adolescence. Arch Gen Psychiatry 60:837-844. CrossRef Medline

Dmitrieva TN, Oades RD, Hauffa BP, Eggers C (2001) Dehydroepiandrosterone sulphate and corticotrophin levels are high in young male patients with conduct disorder: comparisons for growth factors, thyroid and gonadal hormones. Neuropsychobiology 43:134-140. CrossRef Medline

Dorn LD, Crockett LJ, Petersen AC (1988) The relations of pubertal status to intrapersonal changes in young adolescents. J Early Adolesc 8:405-419. CrossRef

Dorn LD, Dahl RE, Woodward HR, Biro F (2006) Defining the boundaries of early adolescence: a user's guide to assessing pubertal status and pubertal timing in research with adolescents. Appl Dev Sci 10:30-56. CrossRef

Estrada M, Varshney A, Ehrlich BE (2006) Elevated testosterone induces apoptosis in neuronal cells. J Biol Chem 281:25492-25501. CrossRef Medline

Evans AC, Brain Development Cooperative Group (2006) The NIH MRI study of normal brain development. Neuroimage 30:184-202. CrossRef Medline
Fair DA, Cohen AL, Power JD, Dosenbach NU, Church JA, Miezin FM, Schlaggar BL, Petersen SE (2009) Functional brain networks develop from a "local to distributed" organization. PLoS Comput Biol 5:e1000381. CrossRef Medline

Fields RD, Burnstock G (2006) Purinergic signalling in neuron-glia interactions. Nat Rev Neurosci 7:423-436. CrossRef Medline

Foradori CD, Weiser MJ, Handa RJ (2008) Non-genomic actions of androgens. Front Neuroendocrinol 29:169-181. CrossRef Medline

Fransson P, Marrelec G (2008) The precuneus/posterior cingulate cortex plays a pivotal role in the default mode network: evidence from a partial correlation network analysis. Neuroimage 42:1178-1184. CrossRef Medline

Giedd JN, Raznahan A, Mills KL, Lenroot RK (2012) Review: magnetic resonance imaging of male/female differences in human adolescent brain anatomy. Biol Sex Differ 3:19. CrossRef Medline

Glantz LA, Gilmore JH, Hamer RM, Lieberman JA, Jarskog LF (2007) Synaptophysin and postsynaptic density protein 95 in the human prefrontal cortex from mid-gestation into early adulthood. Neuroscience 149:582591. CrossRef Medline

Grabner G, Janke AL, Budge MM, Smith D, Pruessner J, Collins DL (2006) Symmetric atlasing and model based segmentation: an application to the hippocampus in older adults. Med Image Comput Comput Assist Interv 9:58-66. Medline

Kabani N, Le Goualher G, MacDonald D, Evans AC (2001) Measurement of cortical thickness using an automated 3-D algorithm: a validation study. Neuroimage 13:375-380. CrossRef Medline

Kaminska M, Harris J, Gijsbers K, Dubrovsky B (2000) Dehydroepiandrosterone sulfate (DHEAS) counteracts decremental effects of corticosterone on dentate gyrus LTP. Implications for depression. Brain Res Bull 52: 229-234. CrossRef Medline

Kancheva R, Hill M, Novák Z, Chrastina J, Kancheva L, Stárka L (2011) Neuroactive steroids in periphery and cerebrospinal fluid. Neuroscience 191:22-27. CrossRef Medline

Karama S, Ad-Dab'bagh Y, Haier R, Deary I, Lyttelton O, Lepage C, Evans A, Brain Development Cooperative Group (2009) Positive association between cognitive ability and cortical thickness in a representative US sample of healthy 6 to 18 year-olds. Intelligence 37:145-155. CrossRef Medline

Karishma KK, Herbert J (2002) Dehydroepiandrosterone (DHEA) stimulates neurogenesis in the hippocampus of the rat, promotes survival of newly formed neurons and prevents corticosterone-induced suppression. Eur J Neurosci 16:445-453. CrossRef Medline

Kessler RC, Berglund P, Demler O, Jin R, Merikangas KR, Walters EE (2005) Lifetime prevalence and age-of-onset distributions of DSM-IV disorders in the National Comorbidity Survey Replication. Arch Gen Psychiatry 62:593-602. CrossRef Medline

Kim JS, Singh V, Lee JK, Lerch J, Ad-Dab'bagh Y, MacDonald D, Lee JM, Kim SI, Evans AC (2005) Automated 3-D extraction and evaluation of the inner and outer cortical surfaces using a Laplacian map and partial volume effect classification. Neuroimage 27:210-221. CrossRef Medline

Kume T, Nishikawa H, Taguchi R, Hashino A, Katsuki H, Kaneko S, Minami M, Satoh M, Akaike A (2002) Antagonism of NMDA receptors by $\sigma$ receptor ligands attenuates chemical ischemia-induced neuronal death in vitro. Eur J Pharmacol 455:91-100. CrossRef Medline

Kurata K, Takebayashi M, Morinobu S, Yamawaki S (2004) $\beta$-Estradiol, dehydroepiandrosterone, and dehydroepiandrosterone sulfate protect against $N$-methyl-D-aspartate-induced neurotoxicity in rat hippocampal neurons by different mechanisms. J Pharmacol Exp Ther 311:237-245. CrossRef Medline

Lacroix C, Fiet J, Benais J, Gueux B, Bonete R, Villette JM, Gourmel B, Dreux C (1987) Simultaneous radioimmunoassay of progesterone, androst-4enedione, pregnenolone, dehydroepiandrosterone and 17-hydroxyprogesterone in specific regions of the human brain. J Steroid Biochem 28:317-325. CrossRef Medline

Laurine E, Lafitte D, Grégoire C, Sérée E, Loret E, Douillard S, Michel B, Briand C, Verdier JM (2003) Specific Binding of Dehydroepiandrosterone to the N Terminus of the Microtubule-associated Protein MAP2. J Biol Chem 278:29979-29986. CrossRef Medline

Lazaridis I, Charalampopoulos I, Alexaki VI, Avlonitis N, Pediaditakis I, Efstathopoulos P, Calogeropoulou T, Castanas E, Gravanis A (2011) Neurosteroid dehydroepiandrosterone interacts with nerve growth factor 
(NGF) receptors, preventing neuronal apoptosis. PLoS Biol 9:e1001051. CrossRef Medline

Lerch JP, Evans AC (2005) Cortical thickness analysis examined through power analysis and a population simulation. Neuroimage 24:163-173. CrossRef Medline

Li Z, Cui S, Zhang Z, Zhou R, Ge Y, Sokabe M, Chen L (2009) DHEAneuroprotection and -neurotoxicity after transient cerebral ischemia in rats. J Cereb Blood Flow Metab 29:287-296. Medline

Lyttelton O, Boucher M, Robbins S, Evans A (2007) An unbiased iterative group registration template for cortical surface analysis. Neuroimage 34: 1535-1544. CrossRef Medline

MacDonald D, Kabani N, Avis D, Evans AC (2000) Automated 3-D extraction of inner and outer surfaces of cerebral cortex from MRI. Neuroimage 12:340-356. CrossRef Medline

Maninger N, Wolkowitz OM, Reus VI, Epel ES, Mellon SH (2009) Neurobiological and neuropsychiatric effects of dehydroepiandrosterone (DHEA) and DHEA sulfate (DHEAS). Front Neuroendocrinol 30:65-91. CrossRef Medline

Marx CE, Jarskog LF, Lauder JM, Gilmore JH, Lieberman JA, Morrow AL (2000) Neurosteroid modulation of embryonic neuronal survival in vitro following anoxia. Brain Res 871:104-112. CrossRef Medline

Mazziotta JC, Toga AW, Evans A, Fox P, Lancaster J (1995) A probabilistic atlas of the human brain: theory and rationale for its development. The International Consortium for Brain Mapping (ICBM). Neuroimage 2:89-101. CrossRef Medline

Moriguchi Y, Ohnishi T, Mori T, Matsuda H, Komaki G (2007) Changes of brain activity in the neural substrates for theory of mind during childhood and adolescence. Psychiatry Clin Neurosci 61:355-363. CrossRef Medline

Nelson CA, Monk CS, Lin J, Carver LJ, Thomas KM, Truwit CL (2000) Functional neuroanatomy of spatial working memory in children. Developmental Psychology 36:109-116. CrossRef Medline

Nguyen TV, McCracken J, Ducharme S, Botteron KN, Mahabir M, Johnson W, Israel M, Evans AC, Karama S (2013) Testosterone-related cortical maturation across childhood and adolescence. Cereb Cortex 23:1424-1432. CrossRef Medline

Patel MA, Katyare SS (2006) Dehydroepiandrosterone (DHEA) treatment stimulates oxidative energy metabolism in the cerebral mitochondria from developing rats. Int J Dev Neurosci 24:327-334. CrossRef Medline

Patel MA, Katyare SS (2007) Effect of dehydroepiandrosterone (DHEA) treatment on oxidative energy metabolism in rat liver and brain mitochondria. A dose-response study. Clin Biochem 40:57-65. CrossRef Medline

Pérez-Neri I, Montes S, Ojeda-López C, Ramírez-Bermúdez J, Ríos C (2008) Modulation of neurotransmitter systems by dehydroepiandrosterone and dehydroepiandrosterone sulfate: mechanism of action and relevance to psychiatric disorders. Prog Neuropsychopharmacol Biol Psychiatry 32: 1118-1130. CrossRef Medline

Petersen A, Crockett L, Richards M, Boxer A (1988) A self-report measure of pubertal status: reliability, validity, and initial norms. J Youth Adolesc 17:117-133. CrossRef

Pfeifer JH, Lieberman MD, Dapretto M (2007) "I know you are but what am I?!": neural bases of self- and social knowledge retrieval in children and adults. J Cogn Neurosci 19:1323-1337. CrossRef Medline

Rege J, Rainey WE (2012) The steroid metabolome of adrenarche. J Endocrinol 214:133-143. CrossRef Medline

Remer T, Boye KR, Hartmann MF, Wudy SA (2005) Urinary markers of adrenarche: reference values in healthy subjects, aged 3-18 years. J Clin Endocrinol Metab 90:2015-2021. CrossRef Medline

Rentería ME (2012) Cerebral asymmetry: a quantitative, multifactorial, and plastic brain phenotype. Twin Res Hum Genet 15:401-413. CrossRef Medline
Rueda MR, Posner MI, Rothbart MK (2005) The development of executive attention: contributions to the emergence of self-regulation. Dev Neuropsychol 28:573-594. CrossRef Medline

Salat DH, Buckner RL, Snyder AZ, Greve DN, Desikan RS, Busa E, Morris JC, Dale AM, Fischl B (2004) Thinning of the cerebral cortex in aging. Cereb Cortex 14:721-730. CrossRef Medline

Saxe RR, Whitfield-Gabrieli S, Scholz J, Pelphrey KA (2009) Brain regions for perceiving and reasoning about other people in school-aged children. Child Dev 80:1197-1209. CrossRef Medline

Shaw P, Greenstein D, Lerch J, Clasen L, Lenroot R, Gogtay N, Evans A, Rapoport J, Giedd J (2006) Intellectual ability and cortical development in children and adolescents. Nature 440:676-679. CrossRef Medline

Sled JG, Zijdenbos AP, Evans AC (1998) A nonparametric method for automatic correction of intensity nonuniformity in MRI data. IEEE Trans Med Imaging 17:87-97. CrossRef Medline

Stanczyk FZ (2006) Measurement of androgens in women. Semin Reprod Med 24:078-085. CrossRef

Suzuki M, Wright LS, Marwah P, Lardy HA, Svendsen CN (2004) Mitotic and neurogenic effects of dehydroepiandrosterone (DHEA) on human neural stem cell cultures derived from the fetal cortex. Proc Natl Acad Sci U S A 101:3202-3207. CrossRef Medline

Szaflarski JP, Schmithorst VJ, Altaye M, Byars AW, Ret J, Plante E, Holland SK (2006) A longitudinal functional magnetic resonance imaging study of language development in children 5 to 11 years old. Ann Neurol 59:796807. CrossRef Medline

Talairach J, Tournoux P (1988) Co-planar stereotaxic atlas of the human brain: 3-dimensional proportional system: an approach to cerebral imaging. New York: Thieme.

Van Goozen SH, Van Den Dan E, Matthys W, Cohen-Kettenis PT, Thijssen $\mathrm{JH}$, Van Engeland H (2000) Increased adrenal androgen functioning in children with oppositional defiant disorder: a comparisn with psychiatric and normal controls. J Am Acad Child Adolesc Psychiatry 39:1446-1451. CrossRef Medline

Vasconsuelo A, Pronsato L, Ronda AC, Boland R, Milanesi L (2011) Role of $17 \beta$-estradiol and testosterone in apoptosis. Steroids 76:1223-1231. CrossRef Medline

Vining RF, McGinley RA (1987) The measurement of hormones in saliva: possibilities and pitfalls. J Steroid Biochem 27:81-94. CrossRef Medline

Waber DP, De Moor C, Forbes PW, Almli CR, Botteron KN, Leonard G, Milovan D, Paus T, Rumsey J, Group BDC (2007) The NIH MRI study of normal brain development: performance of a population based sample of healthy children aged 6 to 18 years on a neuropsychological battery. J Int Neuropsychol Soc 13:729-746. Medline

Wichstrøm L (1999) The emergence of gender difference in depressed mood during adolescence: the role of intensified gender socialization. Dev Psychol 35:232-245. CrossRef Medline

Worsley K, Taylor J, Tomaiuolo F, Lerch J (2004) Unified univariate and multivariate random field theory. Neuroimage 23[Suppl 1]:S189-S195. Medline

Zatorre RJ, Fields RD, Johansen-Berg H (2012) Plasticity in gray and white: neuroimaging changes in brain structure during learning. Nat Neurosci 15:528-536. CrossRef Medline

Zhang L, Li Bs, Ma W, Barker JL, Chang YH, Zhao W, Rubinow DR (2002) Dehydroepiandrosterone (DHEA) and its sulfated derivative (DHEAS) regulate apoptosis during neurogenesis by triggering the Akt signaling pathway in opposing ways. Mol Brain Res 98:58-66. CrossRef Medline

Zijdenbos AP, Forghani R, Evans AC (2002) Automatic "pipeline" analysis of 3-D MRI data for clinical trials: application to multiple sclerosis. IEEE Trans Med Imaging 21:1280-1291. CrossRef Medline 